\title{
Low-Temperature Synthesis of Solution Processable Carbon Nitride Polymers
}

\author{
Junyi Li $^{1}{ }^{1}$, Neeta Karjule ${ }^{1} \mathbb{C}$, Jiani Qin ${ }^{1}$, Ying Wang ${ }^{1}$, Jesús Barrio ${ }^{1,2, *(\mathbb{C}}$ and Menny Shalom ${ }^{1, * \mathbb{C}}$ \\ 1 Department of Chemistry and Ilse Katz Institute for Nanoscale Science and Technology, \\ Ben-Gurion University of the Negev, Beer-Sheva 8410501, Israel; lij@post.bgu.ac.il (J.L.); \\ karjule@post.bgu.ac.il (N.K.); qin@post.bgu.ac.il (J.Q.); wangyin@post.bgu.ac.il (Y.W.) \\ 2 Department of Materials, Royal School of Mines, Imperial College London, London SW72AZ, UK \\ * Correspondence: j.barrio-hermida@imperial.ac.uk (J.B.); mennysh@bgu.ac.il (M.S.)
}

check for updates

Citation: Li, J.; Karjule, N.; Qin, J.; Wang, Y.; Barrio, J.; Shalom, M. Low-Temperature Synthesis of Solution Processable Carbon Nitride Polymers. Molecules 2021, 26, 1646. https://doi.org/10.3390/ molecules26061646

Academic Editor: Yucheng Lan

Received: 22 February 2021

Accepted: 14 March 2021

Published: 16 March 2021

Publisher's Note: MDPI stays neutral with regard to jurisdictional claims in published maps and institutional affiliations.

Copyright: (c) 2021 by the authors. Licensee MDPI, Basel, Switzerland. This article is an open access article distributed under the terms and conditions of the Creative Commons Attribution (CC BY) license (https:// creativecommons.org/licenses/by/ $4.0 /)$.

\begin{abstract}
Carbon nitride materials require high temperatures $\left(>500{ }^{\circ} \mathrm{C}\right)$ for their preparation, which entails substantial energy consumption. Furthermore, the high reaction temperature limits the materials' processability and the control over their elemental composition. Therefore, alternative synthetic pathways that operate under milder conditions are still very much sought after. In this work, we prepared semiconductive carbon nitride $(\mathrm{CN})$ polymers at low temperatures $\left(300{ }^{\circ} \mathrm{C}\right)$ by carrying out the thermal condensation of triaminopyrimidine and acetoguanamine under a $\mathrm{N}_{2}$ atmosphere. These molecules are isomers: they display the same chemical formula but a different spatial distribution of their elements. X-ray photoelectron spectroscopy (XPS) experiments and electrochemical and photophysical characterization confirm that the initial spatial organization strongly determines the chemical composition and electronic structure of the materials, which, thanks to the preservation of functional groups in their surface, display excellent processability in liquid media.
\end{abstract}

Keywords: polymeric carbon nitride; low-temperature synthesis; solution-processable polymers

\section{Introduction}

In the last decade, materials based on graphitic carbon nitride $(\mathrm{CN})$ have attracted extensive attention for their potential application as catalysts for various reactions such as water splitting [1-4], $\mathrm{CO}_{2}$ reduction [5,6], organic pollutant degradation [7], and organic transformations [8-10] in sensing [11-13] and in other fields [14], owing to their photo- and electro-catalytic properties, stability under harsh chemical conditions, easy synthesis, and low cost.

One drawback of polymeric $\mathrm{CN}$ is that high temperatures $\left(>500{ }^{\circ} \mathrm{C}\right)$ are required for its synthesis. Moreover, the insolubility of $\mathrm{CN}$ in most solvents hinders its further processability and deposition on substrates that cannot stand high temperatures (e.g., plastic, membranes) $[15,16]$. Synthesizing CN materials at lower temperatures would reduce the needed energy, and therefore, the cost of the final materials. Furthermore, at low reaction temperatures, only partial condensation is achieved; $\mathrm{CN}$ polymers of a smaller molecular size are obtained, with preserved functional groups that would be otherwise released at higher calcination temperatures. As a result, the dispersibility, and hence, the solution processability of such $\mathrm{CN}$ materials, is expected to be improved.

In recent years, our group and others have shown that the condensation of supramolecular assemblies comprising carbon- and nitrogen-based building blocks with high $\mathrm{C} / \mathrm{N}$ ratios can lead to the formation of semiconducting polymers with photocatalytic properties that are adapted for the degradation of organic pollutants, water splitting, or $\mathrm{CO}_{2}$ reduction [17-22]. A major factor in the design of the $\mathrm{CN}$ material properties lies in the starting $\mathrm{C} / \mathrm{N}$ ratio in the reactant(s). However, the spatial arrangement of the atoms within the molecule and its influence on the final optical, structural, and catalytic properties of $\mathrm{CN}$ 
materials has rarely been discussed [23-25]. Their processability has also not been studied until now.

In this work, we synthesized semiconducting $\mathrm{CN}$ polymers by the thermal condensation of acetoguanamine (AGA) and 2,4,6-triaminopyrimidine (TAP) at various temperatures $[26,27]$. These organic molecules are structural isomers, i.e., they have the same molecular formula but a different spatial arrangement of their atoms; upon condensation, their polymerization pathway differs, leading to distinct materials with different electronic structures and chemical compositions. This allowed us to correlate the properties of the materials with the initial chemical structure of the reactants and show the potential of said materials in different photoelectrocatalytic scenarios.

\section{Results}

While monomers such as TAP and AGA have been shown taking part in melaminecyanuric acid assemblies for modulating the electronic structure of the resulting CNs, up to now they have not been studied as a single precursor for the preparation of photoactive $\mathrm{CN}$ polymers. To do so, TAP and AGA were heated at different temperatures to afford the materials pictured in Figure S1 (AGA300, for example, is the material prepared by the condensation of AGA at $30{ }^{\circ} \mathrm{C}$ ). Fourier-transform infrared spectroscopy (FTIR) analysis (Figure 1a,b) suggested the formation of polymeric materials. The initial monomers showed bands at $2900-3500 \mathrm{~cm}^{-1}$, assigned to $\mathrm{N}-\mathrm{H}$ stretching; the strong peaks between 1200 and $1700 \mathrm{~cm}^{-1}$ were typical of stretching vibrations of triazine rings; the sharp peak at 806 $\mathrm{cm}^{-1}$ corresponded to the breathing vibration of the triazine group [28]. At $300{ }^{\circ} \mathrm{C}$, the peaks corresponding to amino groups in AGA300 and TAP300 became broader and weaker, suggesting the occurrence of at least some condensation. Upon calcination at $400^{\circ} \mathrm{C}$, those vibrations vanished, indicating the successful formation of a polymeric structure at $400{ }^{\circ} \mathrm{C}$.
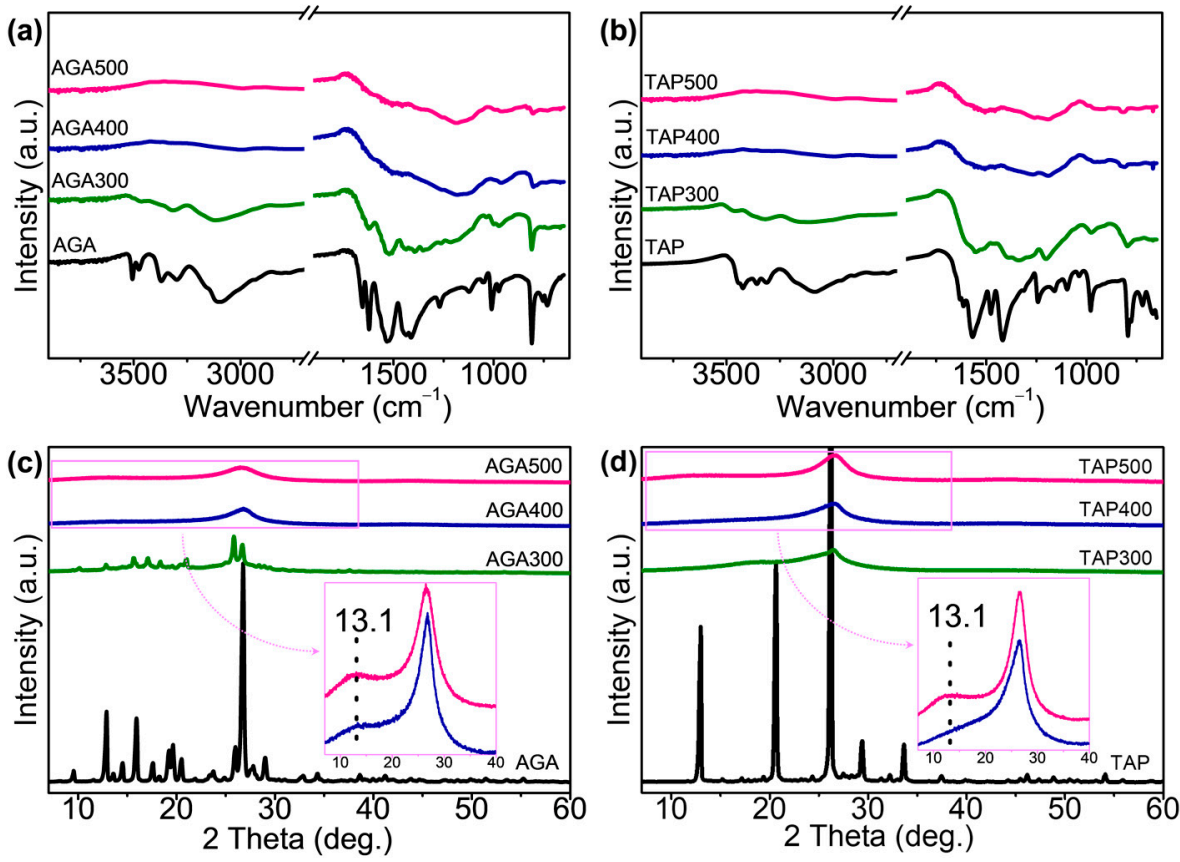

Figure 1. Fourier-transform infrared spectroscopy (FTIR) spectra of (a) acetoguanamine (AGA)- and (b) 2,4,6-triaminopyrimidine (TAP)-derived materials. X-ray diffraction analysis (XRD) patterns of (c) AGA- and (d) TAP-derived materials. The inserts in (c) and (d) are enlarged views of the corresponding area.

X-ray diffraction analysis $(X R D$, Figure $1 \mathrm{c}, \mathrm{d})$ of the products condensed at $300{ }^{\circ} \mathrm{C}$ disclosed that significant changes in the crystal structure already occurred at this temperature. Interestingly, AGA300 showed more diffraction peaks than TAP300, which may be due to the presence of the methyl group outside the triazine ring producing additional 
periodic structures during the incomplete polymerization [20,29]. AGA400 and TAP400 both exhibited a strong peak at $26.5^{\circ}$ and a broad peak at $13.1^{\circ}$, attributed to the (002) and (100) planes of the graphitic structures, respectively. The corresponding $(d)$ spacing was $0.335 \mathrm{~nm}$, which matched well with the $d_{002}$ spacing $(0.34 \mathrm{~nm})$ in the crystalline graphitic $\mathrm{CN}[30]$.

Thermogravimetry analysis (TGA, Figure S2) indicated that both AGA and TAP underwent a dramatic weight loss between 200 and $300^{\circ} \mathrm{C}$, i.e., at a much lower temperature than melamine $\left(400^{\circ} \mathrm{C}\right)$, a typical monomer for the synthesis of polymeric carbon nitride materials $\left(\mathrm{C}_{3} \mathrm{~N}_{4} \mathrm{H}_{\mathrm{x}}\right)[23,31]$. These observations, along with the FTIR and XRD data, suggest a different polymerization route for these monomers-a route that leads to the formation of $\mathrm{CN}$ polymers at lower calcination temperatures than the standard route for carbon nitride materials (Scheme 1).

a)

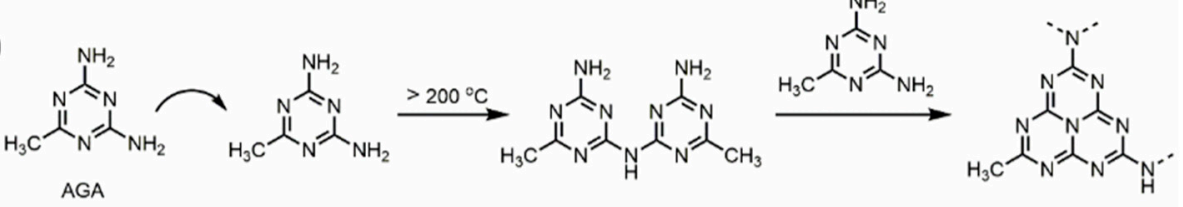

b)

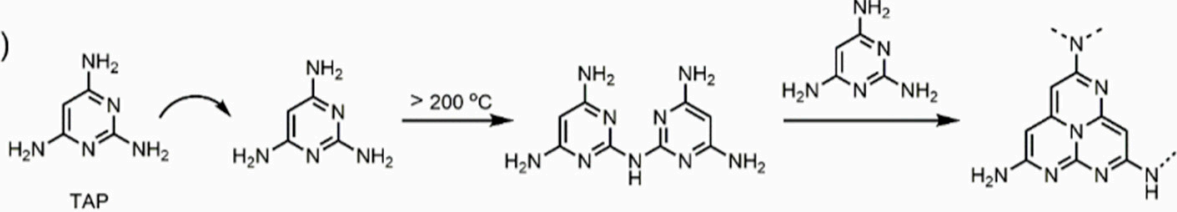

Scheme 1. Proposed structure of the condensation intermediates and final products of the thermal condensation of (a) acetoguanamine and (b) 2,4,6-triaminopyrimidine.

Scanning electron microscopy and transmission electron microscope (SEM and TEM, Figures S3 and S4) showed that AGA-derived materials presented a granular morphology, with particles that become hollow and porous at higher calcination temperatures. In contrast, TAP-derived materials displayed a smooth homogeneous surface. The size of both the AGA-and TAP-derived materials was significantly reduced compared with their corresponding precursors (Figure S5). $\mathrm{N}_{2}$ adsorption-desorption isotherms of AGA- and TAP-derived materials (Figure S6) revealed that the Brunauer-Emmett-Teller (BET) surface area of all these samples was small.

${ }^{1} \mathrm{H}$ and ${ }^{13} \mathrm{C}$ nuclear magnetic resonance (NMR) experiments were carried out to elucidate the structure of the materials obtained by calcination of the monomers at $300{ }^{\circ} \mathrm{C}$. The ${ }^{1} \mathrm{H}$ NMR spectrum of the monomer AGA contained two signals attributable to the primary amine $-\mathrm{NH}_{2}$ at $6.65 \mathrm{ppm}$ and the $-\mathrm{CH}_{3}$ groups at $2.05 \mathrm{ppm}$ (Figure S7). After the calcination of AGA at $300{ }^{\circ} \mathrm{C}$, the NMR spectrum showed a broadening of the peak at 6.62-6.67 ppm, which suggests the formation of at least some oligomers in AGA300, and the $-\mathrm{CH}_{3}$ groups were preserved [32]. The newly formed broad peak at 7.12-7.39 $\mathrm{ppm}$, which belonged to the $-\mathrm{NH}$ protons, suggested the formation of linear polymers of heptazine linked by $-\mathrm{N}(\mathrm{H})$ groups forming $\mathrm{CN}$ sheets (Scheme 1). The spectrum of the other monomer, TAP, displayed three signals: (a) at $4.84 \mathrm{ppm}$ for $-\mathrm{CH}$, (b) at $5.36 \mathrm{ppm}$ for the $-\mathrm{NH}_{2}$ in para position to the $\mathrm{CH}$, and (c) at $5.54 \mathrm{ppm}$ for the other two $-\mathrm{NH}_{2}$. The peaks in the TAP300 spectrum were shifted downfield and were broader than those observed for its monomer (Figure S8). Additionally, $-\mathrm{NH}$ protons of the formed $\mathrm{CN}$ sheets showed a downfield shift with a broad signal at 6.01-6.32 ppm. The ${ }^{13} \mathrm{C}$ NMR spectra of AGA300 and TAP300, which showed characteristic peaks of the monomeric unit, also confirmed the formation of a polymer with AGA and TAP repeating units (further discussed in Figures S9 and S10).

Overall, the results suggested that both monomers underwent incomplete polymerization at $300{ }^{\circ} \mathrm{C}$, resulting in intermediate structures of $\mathrm{CN}$ polymers, as shown in Scheme 1 [33]: the signals for the various $-\mathrm{NH}_{2}$ units of these structures were superim- 
posed on one another, causing a broadening and a downfield shift of peaks in the ${ }^{1} \mathrm{H}$ NMR spectra. Thanks to the remaining $-\mathrm{NH}_{2}$ groups after the partial condensation, the materials were solution-processable in various organic solvents (Figure S11).

X-ray photoelectron spectroscopy (XPS) was carried out to further characterize the chemical states of $\mathrm{C}$ and $\mathrm{N}$ in AGA- and TAP-derived materials. All the high-resolution $\mathrm{C}$ 1s spectra for AGA-derived materials could be deconvoluted in three different chemical binding energies (Figure S12) at 284.8, 286.7, and $287.7 \mathrm{eV}$, corresponding to $\mathrm{sp}^{2} \mathrm{C}-\mathrm{C}$ within the structure and adventitious carbon, the methyl moiety, and $\mathrm{sp}^{2}$-hybridized carbon bonded to nitrogen within the triazine ring $(\mathrm{N}-\mathrm{C}=\mathrm{N})$, respectively. In the case of the TAPderived materials, the $\mathrm{C} 1 \mathrm{~s}$ spectra were deconvoluted into four peaks (Figure S13) at 284.8, $286.2,287.2$, and $288.2 \mathrm{eV}$, corresponding to adventitious carbon, $\mathrm{C}-\mathrm{C}=\mathrm{C}$ bonds inside the ring, sp ${ }^{2}$-hybridized carbon bonded to nitrogen in aromatic rings $(\mathrm{N}-\mathrm{C}=\mathrm{N})$, and $\mathrm{C}-\mathrm{C}=\mathrm{N}$ bonds, respectively [34]. The XPS C 1s spectra of both AGA- and TAP-derived materials remained nearly unchanged at the different calcination temperatures, indicating that the carbon-containing functional groups were largely retained during the polymerization process. The two peaks in the N 1s XPS spectra of AGA300 and TAP300, shown in Figure $\mathrm{S} 14$, at 398.5 and $399.5 \mathrm{eV}$, can be respectively assigned to $\mathrm{sp}^{2}$-nitrogen atoms in triazine rings $(\mathrm{C}-\mathrm{N}=\mathrm{C})$ and amine groups. At $400{ }^{\circ} \mathrm{C}$ and $500{ }^{\circ} \mathrm{C}$, the new peak at $400.7 \mathrm{eV}$ can be attributed to the partially hydrogenated $\mathrm{N}$ atoms of $\mathrm{NH}$, resulting from the partial condensation of amines. Finally, the peak at 399.7 corresponded to $\mathrm{N}-(\mathrm{C})_{3}$ rather than the above neutral amines (at $399.5 \mathrm{eV}$ ) since no primary amino group was present according to the FTIR results. The N 1s XPS peaks of AGA and TAP were similar, and both confirmed the condensation phenomenon with increasing calcination temperature.

These results are consistent with the proposed intermediate structures shown in Scheme 1. The C/N mass ratios (Table S1) of AGA- and TAP-derived materials, calculated from the elemental analysis (EA) results, increased gradually with higher calcination temperatures, suggesting an increasing higher condensation degree in line with the FTIR and XRD results. Remarkably, from $400{ }^{\circ} \mathrm{C}$ to $500{ }^{\circ} \mathrm{C}$, the $\mathrm{C} / \mathrm{N}$ mass ratio of AGA500 remained almost unchanged, whereas the $\mathrm{C} / \mathrm{N}$ mass ratio of TAP500 substantially increased; this may be due to the complete insertion of $\mathrm{C}=\mathrm{C}$ moieties in a $\mathrm{CN}$-like polymer, replacing the typical triazine units. The comparison of these two isomers demonstrated that the spatial organization of the atoms in the initial $\mathrm{CN}$ monomer(s) strongly affects the structure of the final polymer and, therefore, its overall properties.

We further analyze this fact by comparing the condensation of melamine (MA) and 2,4,5,6-tetraaminopyrimidine (TtAP) (structures in Figure S15), which have a similar structure, with one nitrogen from the aromatic ring of MA being substituted by a primary amine-substituted carbon in TtAP. This additional carbon and the higher tendency of amine groups to be released upon thermal condensation resulted in a $\mathrm{C}$-rich material with a condensation temperature as low as $400^{\circ} \mathrm{C}$, while melamine showed features of melem-like moieties [35]. Hence, the position and type of nitrogen are critical, particularly because the $\mathrm{NH}_{2}$ groups are more thermally labile and may be eliminated during the condensation, while the nitrogen atoms of the aromatic ring are more likely to remain in the final material after calcination. Further discussion and characterization of these materials can be found in the Supporting Information (Figures S16-S18). Hereafter, we focused our study on the implications of the spatial location of the atoms from AGA and TAP on the final CN materials' properties.

Ultraviolet-visible spectroscopy (UV-vis) absorption spectroscopy (Figure 2a,b) of the AGA- and TAP-based materials revealed that all samples showed a semiconductor-like behavior; they displayed narrow band gaps compared to standard $\mathrm{CN}$ [1], making them particularly suitable for photocatalytic reactions. The absorption band edges of both AGAand TAP-derived materials showed a red shift upon higher calcination temperatures; this was also reflected by the color of the samples (Figure S1). This red shift was a consequence of the narrowing of the band gap of the materials (Figure S19) at the higher calcination temperatures, owing to further condensation and changes in the $\mathrm{C} / \mathrm{N}$ ratio. 

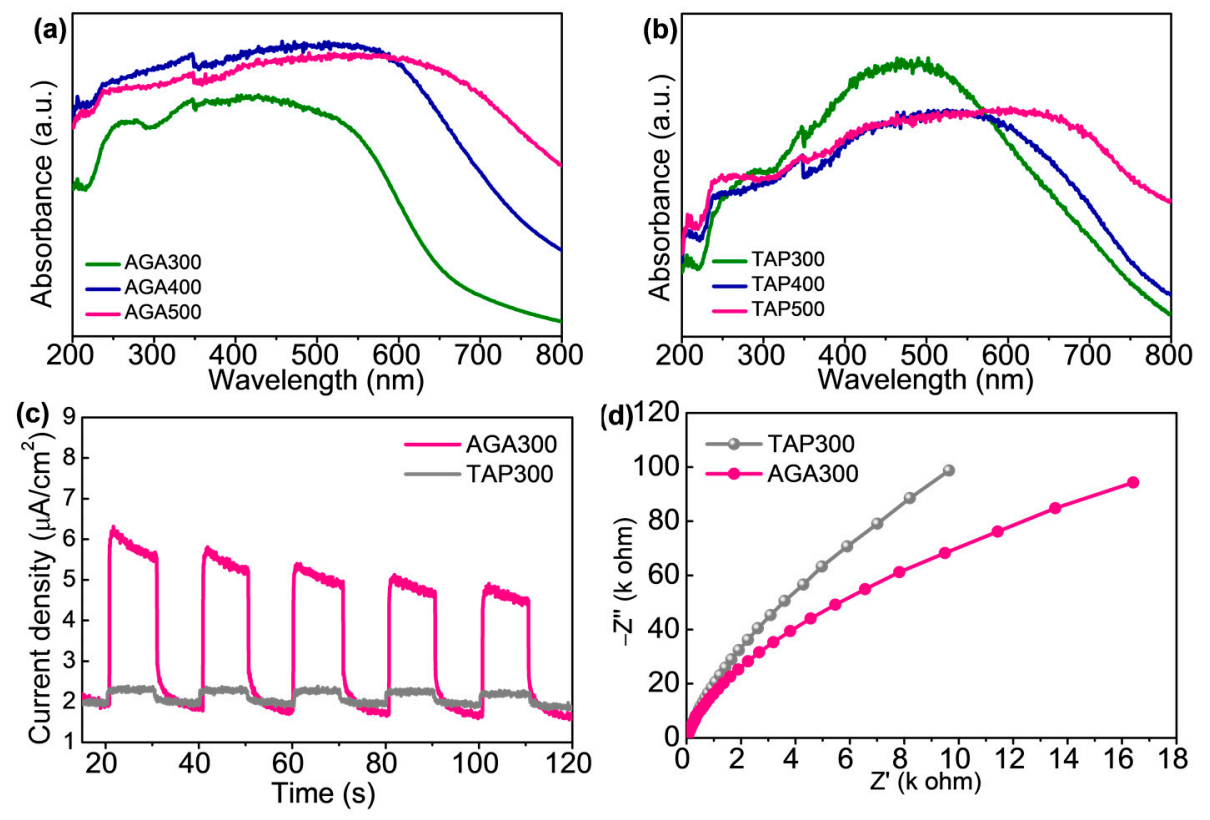

Figure 2. Ultraviolet-visible spectroscopy (UV-vis) absorbance spectra of (a) AGA- and (b) TAPderived materials. (c) Transient photocurrent responses and (d) Nyquist electrochemical impedance spectroscopy (EIS) plots of AGA300 and TAP300.

The processability of $\mathrm{CN}$ polymers is usually quite challenging on account of their low solubility in most solvents, which hinders the obtention by solution-based methods of thin films for photoelectronic devices [36-39]. The processability of the new materials was illustrated by dispersing them in ethanol and drop-casting the suspension on conductive glass to form high-quality films (resulting electrodes in Figure S20). The semiconducting character of the materials obtained at the low calcination temperature resulted in films suitable for photoelectrochemical measurements; we evaluated the charge separation efficiency of photogenerated electron-hole pairs by measuring the generated photocurrent in a standard photoelectrochemical cell $[4,40]$ and by using electrochemical impedance spectroscopy (EIS). As shown in Figure 2c, the photocurrent density of AGA300 was higher than that of TAP300, reaching up to $6 \mu \mathrm{A} \mathrm{cm}{ }^{-2}$. Additionally, the arc radius of the EIS Nyquist plot (Figure 2d) of AGA300 was considerably smaller than that of TAP300, indicating a lower charge transfer resistance. The electrodes of AGA- and TAPderived materials prepared at a higher calcination temperature were not suitable for the solution-based formation of films: the material peeled off the electrode on contact with the electrolyte. Although the observed photocurrent values were not as high as those reported in the literature for other $\mathrm{CN}$-based materials, to the best of our knowledge, this is the first report showing photocurrent generation from a semiconducting $\mathrm{CN}$ polymer prepared at such a low calcination temperature.

We also evaluated the photoactivity of the samples by monitoring their ability to degrade the dye rhodamine $B(R h B)$ under visible light. As shown in Figure $3 a, b$, both AGA- and TAP-derived materials showed photocatalytic degradation, even those made at a condensation temperature of only $300^{\circ} \mathrm{C}$-a very low calcination temperature compared to that commonly used to synthesize semiconductor $\mathrm{CN}$ polymers $[14,15]$. The photocatalytic degradation reaction kinetics were quantified by fitting the data to a pseudofirst-order kinetic equation (with correlation coefficients of $R^{2}>0.95$, Figure S21) [41]. The kinetic degradation rate $k$ of AGA materials prepared at various temperatures followed the order of AGA500 $\left(42.9 \times 10^{-3} \mathrm{~min}^{-1}\right)>$ AGA400 $\left(11.7 \times 10^{-3} \mathrm{~min}^{-1}\right)>$ AGA300 $\left(6.9 \times 10^{-3} \mathrm{~min}^{-1}\right)$, in line with the $\mathrm{C} / \mathrm{N}$ ratios (Figure 3c). In contrast, the $k$ rate of TAP-derived materials followed the order TAP $400\left(8.3 \times 10^{-3} \mathrm{~min}^{-1}\right)>$ TAP500 $\left(4.5 \times 10^{-3} \mathrm{~min}^{-1}\right)>$ TAP300 $\left(3.9 \times 10^{-3} \mathrm{~min}^{-1}\right)$. We attribute this to the modification of the electronic structure owing to a high $\mathrm{C} / \mathrm{N}$ ratio in TAP500 (Figure 3c). We hypoth- 
esized that, while in AGA-based materials the $-\mathrm{CH}_{3}$ groups would act as a functional group in a lattice similar to that of carbon nitride [26], in TAP, the $\mathrm{sp}^{2}$ carbon within the pyrimidinic ring would be retained in the structure of the material, substantially enhancing the conductivity of the material, and modifying its semiconducting behavior (Figure 3d); these changes were confirmed by a Tauc plot (Figure S19) and a Mott-Schottky analysis (Figure S22).
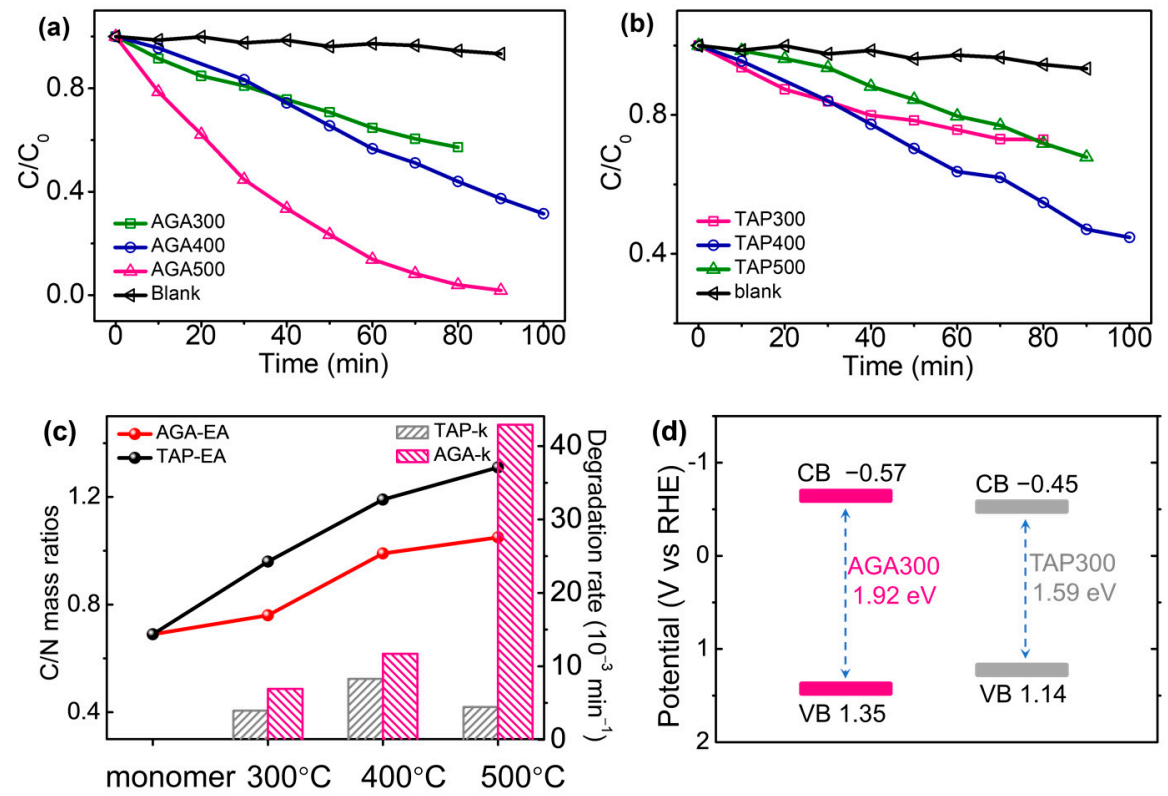

Figure 3. Relative concentration of rhodamine $\mathrm{B}(\mathrm{RhB})$ as a function of illumination time for (a) AGAand (b) TAP-derived materials. (c) $\mathrm{C} / \mathrm{N}$ mass ratios and kinetic degradation rate $k$ as functions of the calcination temperature for AGA- and TAP-derived materials. (d) Estimated band structures of AGA300 and TAP300.

\section{Materials and Methods}

\subsection{Materials Synthesis}

Melamine (MA), acetoguanamine (AGA), 2,4,6-triaminopyrimidine (TAP) and 2,4,5,6tetraaminopyrimidine (TtAP) were used as raw materials without further purification. In a typical reaction, the starting monomer was placed in a ceramic crucible with a lid, then heated to the desired temperature at $4{ }^{\circ} \mathrm{C} / \mathrm{min}$ and kept at this temperature for $4 \mathrm{~h}$ under a $\mathrm{N}_{2}$ atmosphere. The samples were then ground and denoted as AGAT (where $\mathrm{T}$ is the reaction temperature, $\mathrm{T}=300,400,500)$, TAPT $(\mathrm{T}=300,400,500)$, $\mathrm{TtAPT}(\mathrm{T}=300,400)$ and $\operatorname{MAT}(\mathrm{T}=300,400)$, respectively.

\subsection{Materials Characterization}

The Fourier-transform infrared spectroscopy (FTIR) spectra were collected from a Thermo Scientific Nicolet iN 10Mx infrared microscope. X-ray diffraction (XRD) patterns were obtained using an Empyrean powder diffractometer (Panalytical). ${ }^{1} \mathrm{H}$ and ${ }^{13} \mathrm{C}$ NMR spectra were recorded in DMSO- $d_{6}$ on $400 \mathrm{MHz}$ NMR spectrometers (Bruker DPX 400). Scanning electron microscopy (SEM) images were taken at $3 \mathrm{kV}$ with a JEOL JSM-7400F system equipped with a Thermo Scientific NORAN System SIX. Ultraviolet-visible spectroscopy (UV-Vis) spectra were recorded using a Cary 100 spectrophotometer. X-ray photoelectron spectroscopy (XPS) was performed on a Thermo Fisher Scientific ESCALAB 250 using monochromated $\mathrm{Al} \mathrm{K} \alpha$ X-rays $(1486.6 \mathrm{eV})$. Charging effects were corrected by calibrating the spectra relative to the carbon $\mathrm{C1}^{\prime}$ s peak, positioned at $284.8 \mathrm{eV}$. Elemental analysis (EA) results were collected using a Thermo Scientific Flash Smart elemental analyzer OEA 2000. 


\subsection{Dye Degradation Experiments}

The photocatalytic activity was initially evaluated by measuring the photodegradation of the rhodamine $\mathrm{B}(\mathrm{RhB})$ dye under white-light irradiation (Bridge lux BXRA-50 C5300; $\lambda>410 \mathrm{~nm})$. In a typical experiment, an aqueous $\mathrm{RhB}$ solution $(20 \mathrm{~mL}, 10 \mathrm{mg}$ $\left.\mathrm{L}^{-1}\right)$ and the desired material $(20 \mathrm{mg})$ were mixed in a glass vial in the dark and under continuous stirring until an adsorption-desorption equilibrium was reached. After turning on the light, aliquots were withdrawn from the suspension at regular time intervals. The remaining concentration of the RhB dye was monitored by optical absorption (measured at $\lambda_{\max }=554 \mathrm{~nm}$ ) and plotted as the normalized concentration $C / C_{0}$. The photocatalytic degradation reaction kinetics in both cases were quantified by the following pseudo-firstorder kinetic Equation (1):

$$
\ln \left(C / C_{0}\right)=-k t
$$

where $k$ is the apparent kinetic rate constant and $C_{0}$ and $C$ are the initial concentration at $t=0$ and instantaneous concentration of $\mathrm{RhB}$ solution at irradiation time $t$, respectively.

\subsection{Electrochemical Measurements}

Electrochemical measurements were recorded using a three-electrode system on an Autolab potentiostat (Metrohm, PGSTAT 101). A Pt-foil electrode and an Ag/ AgCl (Saturated $\mathrm{KCl}$ ) electrode were used as the counter and reference electrodes, respectively. Mott-Schottky $\left(1 / \mathrm{C}^{2}\right.$ vs. V) measurements were carried out in a $1 \mathrm{M} \mathrm{Na}_{2} \mathrm{SO}_{4}$ aqueous solution as the electrolyte at a frequency of $2.48 \mathrm{kHz}$ solution.

\section{Conclusions}

In summary, we showed the simple synthesis of solution-processable, photoactive $\mathrm{CN}$ polymers by the polymerization of acetoguanamine or 2,4,6-triaminopyrimidine at low calcination temperatures $\left(300\right.$ and $400{ }^{\circ} \mathrm{C}$ ). Compared to the standard carbon nitride monomers where the carbons are adjacent to the nitrogen (e.g., melamine, urea, etc.), the presence of a carbon linked to another carbon atom (whether inside or outside the triazine ring) resulted in a decrease of the polymerization temperature. Furthermore, we shed light on the correlation between the spatial organization of the carbon and nitrogen atoms on the final structural, optical, and catalytic properties of the material. The new polymeric materials exhibited good activity as photocatalysts and with extended optical response, owing to their narrow bandgap. This work shines light on critical considerations for the rational design from the molecular level of new, solution-processable carbon- and nitrogen-based photocatalysts and films.

Supplementary Materials: Supplementary Materials are available online.

Author Contributions: Conceptualization, J.B., and M.S.; methodology, J.L.; software, J.L., and Y.W.; validation, J.L., N.K., and J.Q.; formal analysis, N.K.; investigation, J.L.; data curation, J.L., N.K., and J.B.; writing—original draft preparation, J.L.; writing—review and editing, J.B., and M.S.; project administration, M.S.; funding acquisition, M.S. All authors have read and agreed to the published version of the manuscript.

Funding: This work was financially supported by the Israel Science Foundation, Grant No. 1161/17 and ISF-NSFC Grant No. 2969/19. This project received funding from the European Research Council (ERC) under the European Union's Horizon 2020 Research and Innovation Programme (Grant Agreement No. 849068).

Acknowledgments: The authors thank Einat Nativ-Roth (IKI electron microscopy unit staff) for the SEM measurements and Jiawei Xia, Jonathan Tzadikov, Liel Abisdris, Rotem Geva, Ayelet Tashakory, Michael Volokh, and Adi Azoulay (Ben-Gurion University of the Negev) for technical support. Junyi Li thanks the financial support from the program of China Scholarships Council.

Conflicts of Interest: The authors declare no conflict of interest.

Sample Availability: Samples are available from the authors. 


\section{References}

1. Wang, X.; Maeda, K.; Thomas, A.; Takanabe, K.; Xin, G.; Carlsson, J.M.; Domen, K.; Antonietti, M. A metal-free polymeric photocatalyst for hydrogen production from water under visible light. Nat. Mater. 2009, 8, 76-80. [CrossRef] [PubMed]

2. Kessler, F.K.; Zheng, Y.; Schwarz, D.; Merschjann, C.; Schnick, W.; Wang, X.; Bojdys, M.J. Functional carbon nitride materialsDesign strategies for electrochemical devices. Nat. Rev. Mater. 2017, 2, 17030. [CrossRef]

3. Lakhi, K.S.; Park, D.-H.; Al-Bahily, K.; Cha, W.; Viswanathan, B.; Choy, J.-H.; Vinu, A. Mesoporous carbon nitrides: Synthesis, functionalization, and applications. Chem. Soc. Rev. 2017, 46, 72-101. [CrossRef] [PubMed]

4. Xiong, W.; Huang, F.; Zhang, R.Q. Recent developments in carbon nitride based films for photoelectrochemical water splitting. Sustain. Energy Fuels 2020, 4, 485-503. [CrossRef]

5. Barrio, J.; Mateo, D.; Albero, J.; García, H.; Shalom, M. A Heterogeneous carbon nitride-Nickel photocatalyst for efficient low-temperature $\mathrm{CO}_{2}$ methanation. Adv. Energy Mater. 2019, 9, 1902738. [CrossRef]

6. Qin, J.; Wang, S.; Ren, H.; Hou, Y.; Wang, X. Photocatalytic reduction of $\mathrm{CO}_{2}$ by graphitic carbon nitride polymers derived from urea and barbituric acid. Appl. Catal. B Environ. 2015, 179, 1-8. [CrossRef]

7. Hasija, V.; Raizada, P.; Sudhaik, A.; Sharma, K.; Kumar, A.; Singh, P.; Jonnalagadda, S.B.; Thakur, V.K. Recent advances in noble metal free doped graphitic carbon nitride based nanohybrids for photocatalysis of organic contaminants in water: A review. Appl. Mater. Today 2019, 15, 494-524. [CrossRef]

8. Khamrai, J.; Ghosh, I.; Savateev, A.; Antonietti, M.; König, B. Photo-Ni-dual-catalytic C( $\left(\mathrm{sp}^{2}\right)$-C $\left(\mathrm{sp}^{3}\right)$ cross-coupling reactions with mesoporous graphitic carbon nitride as a heterogeneous organic semiconductor photocatalyst. ACS Catal. 2020, 10, 3526-3532. [CrossRef]

9. Savateev, A.; Antonietti, M. Heterogeneous organocatalysis for photoredox chemistry. ACS Catal. 2018, 8, 9790-9808. [CrossRef]

10. Savateev, A.; Ghosh, I.; König, B.; Antonietti, M. Photoredox Catalytic organic transformations using heterogeneous carbon nitrides. Angew. Chem. Int. Ed. 2018, 57, 15936-15947. [CrossRef] [PubMed]

11. Dong, Y.; Wang, Q.; Wu, H.; Chen, Y.; Lu, C.H.; Chi, Y.; Yang, H.H. Graphitic carbon nitride materials: Sensing, imaging and therapy. Small 2016, 12, 5376-5393. [CrossRef] [PubMed]

12. Liu, J.; Wang, H.; Antonietti, M. Graphitic carbon nitride "reloaded": Emerging applications beyond (photo)catalysis. Chem. Soc. Rev. 2016, 45, 2308-2326. [CrossRef] [PubMed]

13. $\mathrm{Xu}, \mathrm{J} . ;$ Shalom, M. Conjugated carbon nitride as an emerging luminescent material: Quantum dots, thin films and their applications in imaging, sensing, optoelectronic devices and photoelectrochemistry. ChemPhotoChem 2019, 3, 170-179. [CrossRef]

14. Barrio, J.; Volokh, M.; Shalom, M. Polymeric carbon nitrides and related metal-free materials for energy and environmental applications. J. Mater. Chem. A 2020, 8, 11075-11116. [CrossRef]

15. Ong, W.J.; Tan, L.L.; Ng, Y.H.; Yong, S.T.; Chai, S.P. Graphitic carbon nitride $\left(\mathrm{g}-\mathrm{C}_{3} \mathrm{~N}_{4}\right)$-based photocatalysts for artificial photosynthesis and environmental remediation: Are we a step closer to achieving sustainability? Chem. Rev. 2016, 116, 7159-7329. [CrossRef]

16. Wang, Y.; Wang, X.; Antonietti, M. Polymeric graphitic carbon nitride as a heterogeneous organocatalyst: From photochemistry to multipurpose catalysis to sustainable chemistry. Angew. Chem. Int. Ed. 2012, 51, 68-89. [CrossRef]

17. Li, L.; Zhao, Y.; Antonietti, M.; Shalom, M. New organic semiconducting scaffolds by supramolecular preorganization: Dye intercalation and dye oxidation and reduction. Small 2016, 12, 6090-6097. [CrossRef]

18. Li, L.; Shalom, M.; Zhao, Y.; Barrio, J.; Antonietti, M. Surface polycondensation as an effective tool to activate organic crystals: From "boxed" semiconductors for water oxidation to 1d carbon nanotubes. J. Mater. Chem. A 2017, 5, 18502-18508. [CrossRef]

19. Barrio, J.; Karjule, N.; Qin, J.; Shalom, M. Condensation of supramolecular assemblies at low temperatures as a tool for the preparation of photoactive $\mathrm{C}_{3} \mathrm{~N}_{3} \mathrm{O}$ materials. ChemCatChem 2019, 11, 6295-6300. [CrossRef]

20. Keshavarzi, N.; Cao, S.; Antonietti, M. A new conducting polymer with exceptional visible-light photocatalytic activity derived from barbituric acid polycondensation. Adv. Mater. 2020, 32, 1907702. [CrossRef]

21. Barrio, J.; Shalom, M. Rational design of carbon nitride materials by supramolecular preorganization of monomers. Chem CatChem 2018, 10, 5573-5586. [CrossRef]

22. Zhou, Z.; He, F.; Shen, Y.; Chen, X.; Yang, Y.; Liu, S.; Mori, T.; Zhang, Y. Coupling multiphase-Fe and hierarchical N-doped graphitic carbon as trifunctional electrocatalysts by supramolecular preorganization of precursors. Chem. Commun. 2017, 53, 2044-2047. [CrossRef]

23. Yan, S.C.; Li, Z.S.; Zou, Z.G. Photodegradation performance of g- $\mathrm{C}_{3} \mathrm{~N}_{4}$ fabricated by directly heating melamine. Langmuir 2009, 25, 10397-10401. [CrossRef] [PubMed]

24. Zhang, G.; Zhang, J.; Zhang, M.; Wang, X. Polycondensation of thiourea into carbon nitride semiconductors as visible light photocatalysts. J. Mater. Chem. 2012, 22, 8083-8091. [CrossRef]

25. Dong, F.; Wang, Z.; Sun, Y.; Ho, W.K.; Zhang, H. Engineering the nanoarchitecture and texture of polymeric carbon nitride semiconductor for enhanced visible light photocatalytic activity. J. Colloid Interface Sci. 2013, 401, 70-79. [CrossRef]

26. Shipeng, W.; Man, O.; Qin, Z.; Shule, Z.; Wei, C. Supramolecular synthesis of multifunctional holey carbon nitride nanosheet with high-efficiency photocatalytic performance. Adv. Opt. Mater. 2017, 5, 1700536. [CrossRef]

27. Song, X.; Tang, D.; Chen, Y.; Yin, M.; Yang, Q.; Chen, Z.; Zhou, L. A facile and green combined strategy for improving photocatalytic activity of carbon nitride. ACS Omega 2019, 4, 6114-6125. [CrossRef] 
28. Zhu, H.; Xu, S.A. Preparation and fire behavior of rigid polyurethane foams synthesized from modified urea-melamineformaldehyde resins. RSC Adv. 2018, 8, 17879-17887. [CrossRef]

29. $\mathrm{Xu}, \mathrm{J} . ; \mathrm{Wu}, \mathrm{G} . ;$ Wang, Z.; Zhang, X. Generation of 2D organic microsheets from protonated melamine derivatives: Suppression of the self assembly of a particular dimension by introduction of alkyl chains. Chem. Sci. 2012, 3, 3227-3230. [CrossRef]

30. Tian, L.; Li, J.; Liang, F.; Wang, J.; Li, S.; Zhang, H.; Zhang, S. Molten salt synthesis of tetragonal carbon nitride hollow tubes and their application for removal of pollutants from wastewater. Appl. Catal. B Environ. 2018, 225, 307-313. [CrossRef]

31. Azoulay, A.; Barrio, J.; Tzadikov, J.; Volokh, M.; Albero, J.; Gervais, C.; Amo-Ochoa, P.; García, H.; Zamora, F.; Shalom, M. Synthesis of metal-free lightweight materials with sequence-encoded properties. J. Mater. Chem. A 2020, 8, 8752-8760. [CrossRef]

32. Harrell, M.L.; Bergbreiter, D.E. Using $1 \mathrm{~h} \mathrm{nmr} \mathrm{spectra} \mathrm{of} \mathrm{polymers} \mathrm{and} \mathrm{polymer} \mathrm{products} \mathrm{to} \mathrm{illustrate} \mathrm{concepts} \mathrm{in} \mathrm{organic} \mathrm{chemistry.}$ J. Chem. Educ. 2017, 94, 1668-1673. [CrossRef]

33. Jürgens, B.; Irran, E.; Senker, J.; Kroll, P.; Müller, H.; Schnick, W. Melem (2,5,8-triamino-tri-s-triazine), an important intermediate during condensation of melamine rings to graphitic carbon nitride: Synthesis, structure determination by $\mathrm{x}$-ray powder diffractometry, solid-state NMR, and theoretical studies. J. Am. Chem. Soc. 2003, 125, 10288-10300. [CrossRef]

34. Ho, W.; Zhang, Z.; Lin, W.; Huang, S.; Zhang, X.; Wang, X.; Huang, Y. Copolymerization with 2,4,6-triaminopyrimidine for the rolling-up the layer structure, tunable electronic properties, and photocatalysis of $\mathrm{g}_{-} \mathrm{C}_{3} \mathrm{~N}_{4}$. ACS Appl. Mater. Interfaces 2015, 7 , 5497-5505. [CrossRef] [PubMed]

35. Sattler, A.; Pagano, S.; Zeuner, M.; Zurawski, A.; Gunzelmann, D.; Senker, J.; Müller-Buschbaum, K.; Schnick, W. Melamine-melem adduct phases: Investigating the thermal condensation of melamine. Chem. Eur. J. 2009, 15, 13161-13170. [CrossRef] [PubMed]

36. Karjule, N.; Phatake, R.; Volokh, M.; Hod, I.; Shalom, M. Solution-processable carbon nitride polymers for photoelectrochemical applications. Small Methods 2019, 3, 1900401. [CrossRef]

37. Sun, J.; Phatake, R.; Azoulay, A.; Peng, G.; Han, C.; Barrio, J.; Xu, J.; Wang, X.; Shalom, M. Covalent functionalization of carbon nitride frameworks through cross-coupling reactions. Chem. Eur. J. 2018, 24, 14921-14927. [CrossRef]

38. Kumru, B.; Barrio, J.; Zhang, J.; Antonietti, M.; Shalom, M.; Schmidt, B.V.K.J. Robust carbon nitride-based thermoset coatings for surface modification and photochemistry. ACS Appl. Mater. Interfaces 2019, 11, 9462-9469. [CrossRef]

39. Kumru, B.; Antonietti, M. Colloidal properties of the metal-free semiconductor graphitic carbon nitride. Adv. Colloid Interface Sci. 2020, 283, 102229. [CrossRef]

40. Volokh, M.; Peng, G.; Barrio, J.; Shalom, M. Carbon nitride materials for water splitting photoelectrochemical cells. Angew. Chem. Int. Ed. 2019, 58, 6138-6151. [CrossRef]

41. Tian, L.; Li, J.; Liang, F.; Chang, S.; Zhang, H.; Zhang, M.; Zhang, S. Facile molten salt synthesis of atomically thin boron nitride nanosheets and their co-catalytic effect on the performance of carbon nitride photocatalyst. J. Colloid Interface Sci. 2019, 536, 664-672. [CrossRef] [PubMed] 